\title{
Injury rates during the 1988 US Olympic Team Trials for taekwondo
}

\author{
E.D. Zemper, PhD and W. Pieter, PhD
}

International Institute for Sport and Human Performance, University of Oregon, USA

\begin{abstract}
Injury rates were recorded during the 1988 US Olympic Team Trials for taekwondo involving 48 men and 48 women. The injury rate for men (12.74/100 athlete-exposures) was about 40 per cent higher than the rate for women $(9.01 / 100$ athleteexposures). The foot and the head were the most frequently injured body parts. Contusions were the predominant type of injury, and concussions were recorded for both men and women. A large proportion (41 per cent) of the men's injuries were the result of receiving a blow from an unblocked attack. For the women the most common injury situation (40 per cent) was while attacking with a kick. For both men and women, 15 per cent of the reported injuries were time-loss injuries. The head injuries found in this study are discussed with reference to the high impact velocities and momentum levels generated during taekwondo kicking. Recommendations are made with regard to protective equipment testing and rule changes to reduce the possibility of cerebral injury.
\end{abstract}

Keywords: Injury rates, taekwondo, protective equipment, cerebral injury

\section{Introduction}

The Korean martial art of taekwondo was a demonstration sport at the 1988 Seoul Olympic Games. National, continental and world championships for this sport have been held for several years.

Zandbergen followed a group of nationally and internationally competing Dutch taekwondo athletes for two years' 1 . He recorded the frequencies of injuries and reported that contusions, especially of the lower extremities, were the most frequently occurring injuries, followed by sprains and ruptures, mostly of the lower extremities. Siana $e t$ al. observed that most injuries of those competitors who were admitted to casualty wards (15 cases) during the 6th World Taekwondo Championships in Denmark, were fractures and contusions to the head and neck (nine cases) ${ }^{2}$. In view of the paucity of injury data during taekwondo competition, the purpose of this study was to report injury rates during a national taekwondo tournament.

Address for correspondence: $\mathrm{Dr}$ Eric $\mathrm{D}$. Zemper, International Institute for Sport and Human Performance, University of Oregon, Engene, OR 97403, USA

(C) 1989 Butterworth \& Co (Publishers) Ltd 0306-3674/89/030161-04 \$03.00

\section{Methods}

Data were collected at the 1988 United States Olympic Team Trials for taekwondo. The initial elimination bouts involved six competitors in each of the eight weight divisions for men and women. The finals involved the top two competitors from the eliminations in each weight division. Competitors ranged in age from 15 to 37 years.

Injury data were collected with simple check-off forms developed by the authors to collect information about the competitors and the nature, site, circumstances and severity of the injury. These forms are a variation of forms developed by one of us (EDZ) for use with the National Sports Injury Surveillance System. The forms were completed at the time of injury treatment by the attending physician or by the members of the athletic training staff of the US Olympic Training Center-Colorado Springs. A form was completed for every injury for which treatment was sought by the competitors from the medical staff at the competition site.

Exposure data for calculating injury rates were gathered from records of bouts actually fought. Each bout consisted of three rounds of three minutes each. In cases where bouts were not completed, the rounds completed and time when the bout was stopped were noted. Injury rates were calculated from matches fought and minutes fought using the basic rate formula: (\# injuries/\# athlete-exposures or minutes of exposure $) \times 100=\#$ injuries per 100 athlete-exposures or per 100 minutes of exposure.

\section{Results}

A summary of the exposure and injury rate data is presented in Table 1.

The distribution of injuries by body part is presented in Table 2.

Not surprisingly, contusions were by far the predominant type of injury, as illustrated in Table 3. Contusions comprised 63 per cent of the men's injuries and 75 per cent of the women's. Among the more serious injuries, men recorded four fractures (nose, finger, foot and orbital fracture), and the men and the women each recorded one concussion.

Men and women demonstrated differences in the situations most associated with injury (Table 4). The 
Injury rates during team trials for taekwondo: E.D. Zemper and W. Pieter

Table 1. Competition injury rates for men and women taekwondo participants

\begin{tabular}{lrc}
\hline & Men & Women \\
\hline Matches & 106 & 111 \\
Athlete exposures to the possibility of being & 212 & 222 \\
injured (2 per match) & 1881 & 1983 \\
Minutes exposed & 27 & 20 \\
Reported injuries & & \\
Total injury rates & 12.74 & 9.01 \\
Per 100 athlete-exposures & 1.44 & 1.01 \\
Per 100 minutes exposed & 56.3 & 41.7 \\
Per 100 participants & & \\
\hline
\end{tabular}

Table 2. Distribution of injuries by body part*

\begin{tabular}{lcccc}
\hline \multicolumn{2}{c}{ Men } & \multicolumn{2}{c}{ Women } \\
\hline \multirow{2}{*}{ Body part } & Number & Rate $($ per & & Rate (per \\
& $100 A-E)$ & Number & $100 A-E)$ \\
\hline Head & 1 & 0.47 & 1 & 0.45 \\
Eye(s) & 1 & 0.47 & 1 & 0.45 \\
Nose & 1 & 0.47 & 0 & 0 \\
Face & 1 & 0.47 & 1 & 0.45 \\
Jaw & 0 & 0 & 1 & 0.45 \\
Mouth & 2 & 0.94 & 0 & 0 \\
Clavicle & 1 & 0.47 & 0 & 0 \\
Hand & 4 & 1.89 & 0 & 0 \\
Finger(s) & 1 & 0.47 & 0 & 0 \\
Ribs & 2 & 0.94 & 0 & 0 \\
Sternum & 1 & 0.47 & 0 & 0 \\
Upperleg & 0 & 0 & 3 & 1.35 \\
Hamstrings & 1 & 0.47 & 0 & 0 \\
Knee & 3 & 1.42 & 3 & 1.35 \\
Patella & 0 & 0 & 1 & 0.45 \\
Lowerleg & 3 & 1.42 & 1 & 0.45 \\
Foot & 5 & 2.36 & 8 & 3.6 \\
Total & 27 & 12.74 & 20 & 9.01 \\
\hline
\end{tabular}

${ }^{*}$ Body parts not listed in this Table were not involved in any recorded injuries

Table 3. Distribution of injuries by type of injury*

\begin{tabular}{lcccc}
\hline & \multicolumn{2}{c}{ Men } & \multicolumn{2}{c}{ Women } \\
\hline Injury Type & Number & $\begin{array}{c}\text { Rate (per } \\
100 A-E)\end{array}$ & Number & Rate (per \\
& & & & \\
\hline Abrasion & 1 & 0.47 & 0 & 0 \\
Concussion & 1 & 0.47 & 1 & 0.45 \\
Contusion & 17 & 8.02 & 15 & 6.76 \\
Dislocation & 0 & 0 & 1 & 0.45 \\
Fracture & 4 & 1.89 & 0 & 0 \\
Laceration & 1 & 0.47 & 0 & 0 \\
Sprain & 1 & 0.47 & 1 & 0.45 \\
Strain & 1 & 0.47 & 1 & 0.45 \\
Other & 1 (bitten) & 0.47 & 1 (eye & 0.45 \\
& & & irritation) & \\
Total & 27 & 12.74 & 20 & 9.01 \\
\hline
\end{tabular}

*Injury types not listed in this Table did not occur in this sample

most common situation resulting in injury for the men was suffering an unblocked attack by the opponent (41 per cent), while for the women it was while attacking with a kick ( 40 per cent). Table 5 shows the distribution of injuries by mechanism, which is related to the situation as shown in Table 4. For the women, the most predominant injury mechanism was evenly split between delivering and receiving a blow (35 per cent each), while for the men it was predominantly receiving a
Table 4. Distribution of injuries by situation

\begin{tabular}{lcccc}
\hline & \multicolumn{2}{c}{ Men } & \multicolumn{2}{c}{ Women } \\
\hline \multicolumn{1}{c}{ Situation } & Number & $\begin{array}{c}\text { Rate (per } \\
100 A-E)\end{array}$ & Number & $\begin{array}{l}\text { Rate (per } \\
100 A-E)\end{array}$ \\
\hline Blocking a kick & 6 & 2.83 & 3 & 1.35 \\
Blocking a punch & 1 & 0.47 & 0 & 0 \\
Attacking-kick & 5 & 2.36 & 8 & 3.6 \\
Attacking-punch & 3 & 1.42 & 0 & 0 \\
Unblocked attack & 11 & 5.19 & 3 & 1.35 \\
Recovering from & & & & 0.45 \\
missed kick & 0 & 0 & 1 & 0.45 \\
Warming up & 0 & 0 & 1 & 1.8 \\
Unknown & 1 & 0.47 & 4 & 9.01 \\
Total & 27 & 12.74 & 20 & \\
\hline
\end{tabular}

Table 5. Distribution of injuries by mechanism

\begin{tabular}{lrccc}
\hline & \multicolumn{2}{c}{ Men } & \multicolumn{2}{c}{ Women } \\
\hline \multicolumn{1}{c}{ Mechanism } & Number & $\begin{array}{l}\text { Rate (per } \\
\text { 100A-E) }\end{array}$ & Number & $\begin{array}{c}\text { Rate (per } \\
100 A-E)\end{array}$ \\
\hline Delivering blow & 8 & 3.78 & 7 & 3.15 \\
Receiving blow & 17 & 8.02 & 7 & 3.15 \\
Impact with surface & 1 & 0.47 & 0 & 0 \\
No evidence of contact & 0 & 0 & 1 & 0.45 \\
Overuse/gradual onset & 0 & 0 & 1 & 0.45 \\
Twisting on leg & 0 & 0 & 1 & 0.45 \\
Unknown & 1 & 0.47 & 3 & 1.35 \\
Total & 27 & 12.74 & 20 & 9.01 \\
\hline
\end{tabular}

Table 6. Time-loss injury rates of taekwondo compared with other sports*

\begin{tabular}{lclc}
\hline & \multicolumn{2}{c}{ Men } & \multicolumn{2}{c}{ Women } \\
\hline & $\begin{array}{c}\text { Competition } \\
\text { Spjury rate } \\
\text { Spert } 1000 A-E)\end{array}$ & Sport & $\begin{array}{c}\text { Competition } \\
\text { injury rate } \\
\text { (per 1000A-E) }\end{array}$ \\
\hline Wrestling & 31.75 & Gymnastics & 18.09 \\
American football & 30.97 & Football (Soccer) & 15.31 \\
Taekwondo & 23.58 & Taekwondo & 13.51 \\
Football (Soccer) & 18.67 & Field hockey & 7.22 \\
Ice hockey & 15.72 & Lacrosse & 6.99 \\
Gymnastics & 14.66 & Softball & 5.31 \\
Lacrosse & 13.89 & Volleyball & 4.55 \\
Baseball & 4.92 & & \\
\hline
\end{tabular}

*Injury rates for all sports in this Table, except taekwondo, were taken from the National Collegiate Athletic Association injury report summary for 1986-1987 and 1987-1988 academic years (NCAA News, 30 October 1988, p. 1)

blow (63 per cent). Combining the information from Tables 4 and 5, it appears that the women tended to be injured more during offensive moves, while the men were injured more often as a result of defensive moves or the lack thereof.

For the purposes of this study, we recorded any injury that was brought to the medical staff for treatment during the competition. As would be expected, most of the recorded injuries were not of sufficient severity to keep the athlete from continuing to compete in the tournament. A more common definition of a reportable injury used in studies of the epidemiology of sport injuries is one that results in the athlete missing one or more days of participation (practice or competition) following the injury ${ }^{3,4}$. 
In this study, there were four such time-loss injuries among the men and three among the women. For both the men and the women, 15 per cent of the reported injuries were time-loss injuries. Using these figures to calculate injury rates per 1000 athlete-exposures results in an injury rate for taekwondo competition of 23.58/1000 Athlete-Exposures (A-E) for men, and 13.51/1000 A-E for women. Table 6 provides a comparison of the time-loss competition injury rates for taekwondo with similarly calculated competition injury rates for several American college sports.

For most sports where such data are available, the injury rates during competition range from three to nine times higher than injury rates during practice sessions $^{3}$.

\section{Discussion}

Several other studies have found contusions to be the most frequently occurring type of injury in martial arts in which kicks and punches are used ${ }^{1,5,6}$. The subjects in Stricevic's study were noncontact karate athletes, as opposed to those in the present study who were fullcontact taekwondo athletes. For the women in this study, all foot injuries were contusions, whereas for the men, all hand and four of the five foot injuries were contusions.

McLatchie reported that one injury occurred in every four noncontact karate matches ${ }^{7}$, while the use of padding (for the fists, arms, legs, feet) and head gear reduced the number of injuries to one in every 22 matches ${ }^{\circ}$. Kurland estimated that about 72 per cent of the injuries sustained during karate practice could have been prevented with adequate padding. In taekwondo, padding is worn not only for the groin, head, upper and lower extremities, but also for the trunk. The men in the present study incurred one injury in every four matches and the women one in every six contests. However, these numbers have to be qualified. The reduction in injuries when protective equipment was used occurred during noncontact competition; the number of injuries is greater when contact is allowed ${ }^{10}$, which would lead one to expect a higher incidence of injuries per taekwondo match.

In view of the distribution of injuries by situation and by mechanism, some observations regarding fighting strategy can be made. The men are advised to improve their blocking skills or to use more evasive manoeuvres to avoid injuries during competition. The women could benefit from improved kicking skills, assuming that injuries sustained while attacking with a kick are related to poor technique.

Birrer et al. mentioned that, in general, severe injuries in martial arts involving kicking and punching occur less frequently than those reported for other contact sports ${ }^{10}$. Examination of Table 6 reveals that injury rates during one taekwondo tournament ranks third in terms of time-loss injury rates when compared to competition injury rates in other sports collected over a two year period. Further taekwondo injury data need to be collected to make more realistic comparisons.

In the present study, using a definition of 'serious' as any injury that keeps an athlete from participating for three weeks or more, two of 47 reported injuries in contact taekwondo were serious, a rate approximately
21 times higher than observed by Birrer et al. for noncontact taekwondo ${ }^{11}$.

It also is important to realize that some 60 per cent of martial arts injuries during competition and practice are not reported ${ }^{12}$. In an earlier publication, Birrer $e t$ al. suggest that this may be due to any or a combination of the following reasons: (i) unreported injuries may be relatively minor (ii) the athlete may think that she is invincible (iii) the instructor may refuse to accept that the athlete is injured ${ }^{5}$.

McLatchie et al. reported that protective padding reduced the number and severity of noncontact karate injuries $^{8}$. They also contended that wearing $16 \mathrm{oz}$ gloves, among other things, would prevent head injury. Experimental studies, however, showed that this may not necessarily be the case, especially if considering full-contact situations. Smith and Smith et al. found that the boxing and karate gloves were not particularly effective in preventing knockouts in boxing or full-contact karate ${ }^{13-16}$. In fact, higher momentum levels were recorded for gloved punches on a heavy bag as compared with bare fisted punches. The karate glove would most likely cause concussions due to the higher impulse values ${ }^{14}$. It spread impact forces over a longer period of time at higher velocities and caused greater accelerations of the impacted object ${ }^{15}$.

It has been hypothesized that, with a head mass of about $5 \mathrm{~kg}$, impulses from $34 \mathrm{~N}$-s to $90 \mathrm{~N}$-s would possibly cause a concussion ${ }^{13}$ as would impact forces greater than around $588 \mathrm{~N}$ that are applied for about 26 to $28 \mathrm{~ms}^{15}$ or head accelerations of $80 \mathrm{G}$ which correspond to forces of $784 \mathrm{~N}$ at about $8 \mathrm{~ms}^{16}$. Since punches to the head and face area are not allowed in full-contact taekwondo, it would be more pertinent to look at the effect of kicking to the head and face, which currently are legitimate targets for kicks.

Schwartz et al. found that foot padding was not sufficient to reduce peak accelerations ${ }^{17}$. It actually resulted in increased accelerations of the head, especially when kicking to the side of the head with a roundhouse kick (the most frequently used in full-contact taekwondo competition). Although the authors did not give any mean values for the different kick and punch conditions in their study, they did mention finding values of $90 \mathrm{G}$ on several occasions with a high of $120 \mathrm{G}$. It would appear that protective equipment, through its cushioning effect, is more beneficial to the athlete executing the blow than it is to the receiver of the blow ${ }^{13,17}$.

Initial results from the biomechanics studies in our current project with elite taekwondo athletes have shown that mean kick velocities before impact varied from about $13 \mathrm{~m} / \mathrm{s}$ for women to about $16 \mathrm{~m} / \mathrm{s}$ for men for the roundhouse kick, while the impact velocities for the reverse punch varied from about $9 \mathrm{~m} / \mathrm{s}$ for women to about $11 \mathrm{~m} / \mathrm{s}$ for men ${ }^{18}$. Bag momentum values for the roundhouse kick varied from 91 N.m for women to 117 N.m for men, while the reverse punch yielded values of $88 \mathrm{~N}$.m for women and $126 \mathrm{~N} . \mathrm{m}$ for men. Higher bag momentum levels are indicative of greater accelerations which in turn are related to brain and tissue damage ${ }^{13}$.

It was estimated that a fist velocity of $8 \mathrm{~m} / \mathrm{s}$ would result in a peak acceleration of the head of about $200 \mathrm{G}$, assuming there is no deflection during the punch ${ }^{19}$. 
From the above mentioned velocity data, it easily can be seen that higher velocities are generated during the roundhouse kick. Such high velocity values and the nature of a rotational kick like the roundhouse kick are associated with subdural haematoma, intracerebral haemorrhages and diffuse axonal injury ${ }^{19}$.

The high velocities and momentum levels generated during taekwondo kicking in combination with a lack of proper blocking as found in this study should give rise to serious concern about the medical implications of full-contact taekwondo. Although protective equipment is now being used as suggested by Siana et al. ${ }^{2}$, it also should be noted that after repeated impact the padding may no longer be adequate. Smith $e t$ al. found that after only the fifth impact during punching the karate glove would no longer give adequate protection, and the impact forces resulting from a punch after the fifth impact would be within the zone of concussion ${ }^{15}$.

\section{Acknowledgements}

The authors would like to thank the US Taekwondo Union for funding part of this study; Jenny Stone and her staff of athletic trainers at the US Olympic Training Center, Colorado Springs, CO and Dr Sam Pejo of Binghamton, NY for their assistance in collecting the data.

\section{References}

1 Zandbergen, A. 'Taekwondo blessures en fysiotherapie' Unpublished thesis, Twentse Akademie voor Fysiotherapie, Enschede

2 Siana, J.E., Borum, P. and Kryger, H. Injuries in taekwondo Br J Sports Med 1986, 20, 165-166

3 Zemper, E.D. 'The NCAA Injury Surveillance System: Initial results' Paper presented at the 1984 Olympic Scientific Congress, Eugene, OR, July 1984

4 Zemper, E.D. A two-year prospective study of injury rates in a national sample of college football teams Phys and Sports Med (in press)

5 Birrer, R.B. and Birrer, C.D. Martial arts injuries Phys and Sports Med 1982, 10, 103-108
6 Stricevic, M.V., Patel, M.R., Okazaki, T. and Swain, B.K. 'Karate: Historical perspective and injuries sustained in national and international tournament competitions Am J Sports Med 1983, 11, 320-324

7 McLatchie, G.R. Analysis of injuries in 295 karate contests Br J Acc Surg 1976, 8, 132-134

8 McLatchie, G.R. and Morris, E.W. Prevention of karate injuries - a progress report Br J Sports Med 1977, 11, 78-82

9 Kurland, H.L. Injuries in karate Phys and Sports Med $1980,8,80-85$

10 Birrer, R.B. and Halbrook, S.P. Martial arts injuries. The results of a five year national survey Am J Sports Med 1988, 16, 408-410

11 Birrer, R.B., Birrer, C.D., Son, D.S. and Stone, D. Injuries in taekwondo Phys and Sports Med 1981, 9, 97-103

12 Birrer, R.B. and Birrer, C.D. Unreported injuries in the martial arts Br J Sports Med 1983, 17, 131-134

13 Smith, P.K. 'Punching impact effect of the karate, boxing, and the thumbless boxing glove, in Terauds, J., Gowitzke, B.E. and Holt, L.E. (eds.), Biomechanics in Sports III \& IV, Academic Publishers, Del Mar, CA, 1987

14 Smith, P.K. 'Transmission of force through the karate, boxing, and thumbless boxing glove as a function of velocity' In Terauds, J., Gowitzke, B.E. and Holt, L.E. (eds.), Biomechanics in Sports III and IV, Academic Publishers, Del Mar, CA, 1987

15 Smith, P.K. and Hamill, J. 'Karate and boxing glove impact characteristics as functions of velocity and repeated impact' In Terauds, J. and Barham, J.N. (eds.) Biomechanics in Sports II, Academic Publishers, Del Mar, CA. 1985

16 Smith, P.K. and Hamill, J. The effect of punching glove type and skill level on momentum transfer J Hum Mov Stud 1986, 12, 153-161

17 Schwartz, M.L., Hudson, A.R., Fernie, G.R., Hayashi, K. and Coleclough, A.A. Biomechanical study of fullcontact karate contrasted with boxing J Neurosurg 1986, 64, 248-252

18 Pieter, W. Athletic profile of Olympic male and female taekwondo athletes. Progress report (Unpublished) International Institute for Sport and Human Performance, Eugene, OR, 1988

19 Whiting, W.C., Gregor, R.J. and Finerman, G.A. Kinematic analysis of human upper extremity movements in boxing Am J Sports Med 1988, 16, 130-136 